\title{
Corrigendum: Historical factors that have shaped the evolution of tropical reef fishes: a review of phylogenies, biogeography, and remaining questions
}

\author{
Peter F. Cowman * \\ Department of Ecology and Evolutionary Biology, Yale University, New Haven, CT, USA
}

Keywords: coral reef fishes, ancestral biogeography, marine tropics, phylogeny, diversification

\section{A corrigendum on}

OPEN ACCESS

Edited by:

James Edward Richardson, Royal Botanic Garden Edinburgh, UK

Reviewed by:

Giacomo Bernardi,

University of California Santa Cruz,

USA

*Correspondence:

Peter F. Cowman,

peter.cowman@yale.edu

Specialty section:

This article was submitted to Evolutionary and Population Genetics,

a section of the journal

Frontiers in Genetics

Received: 24 July 2015 Accepted: 05 September 2015 Published: 15 September 2015

Citation:

Cowman PF (2015) Corrigendum: Historical factors that have shaped the evolution of tropical reef fishes: a review of phylogenies, biogeography, and remaining questions.

Front. Genet. 6:295. doi: 10.3389/fgene.2015.00295
Historical factors that have shaped the evolution of tropical reef fishes: a review of phylogenies, biogeography, and remaining questions

by Cowman, P. F. (2014). Front. Genet. 5:394. doi: 10.3389/fgene.2014.00394

Figure 1A of this manuscript does not have the correct scaling for the distribution of species richness. The correct break values for colors denoting levels of species richness across tropical areas should be: $<250, \geq 500, \geq 1000, \geq 1500, \geq 2000$. This mistake, while not crucial to the discussion is inaccurate based on the dataset examined in this study. A new figure has been generated with correct values. The figure caption remains the same, and there are no associated changes to be made in the main text.

The original article was updated.

\section{References}

Hughes, T. P., Bellwood, D. R., and Connolly, S. R. (2002). Biodiversity hotspots, centres of endemicity, and the conservation of coral reefs. Ecol. Lett. 5, 775-784. doi: 10.1046/j.1461-0248.2002.00383.x

Kulbicki, M., Parravicini, V., Bellwood, D. R., Arias-Gonzàlez, E., Chabanet, P., Floeter, S. R., et al. (2013). Global biogeography of reef fishes: a hierarchical quantitative delineation of regions. PLoS ONE 8:e81847. doi: 10.1371/journal.pone.0081847

Spalding, M. D., Fox, H. E., Allen, G. R., Davidson, N., Ferdaña, Z. A., Finlayson, M., et al. (2007). Marine ecoregions of the world: a bioregionalization of coastal and shelf areas. Bioscience 57, 573. doi: 10.1641/B570707

Conflict of Interest Statement: The author declares that the research was conducted in the absence of any commercial or financial relationships that could be construed as a potential conflict of interest.

Copyright () 2015 Cowman. This is an open-access article distributed under the terms of the Creative Commons Attribution License (CC BY). The use, distribution or reproduction in other forums is permitted, provided the original author(s) or licensor are credited and that the original publication in this journal is cited, in accordance with accepted academic practice. No use, distribution or reproduction is permitted which does not comply with these terms. 


\section{A Species Richness (by ecoregion)}

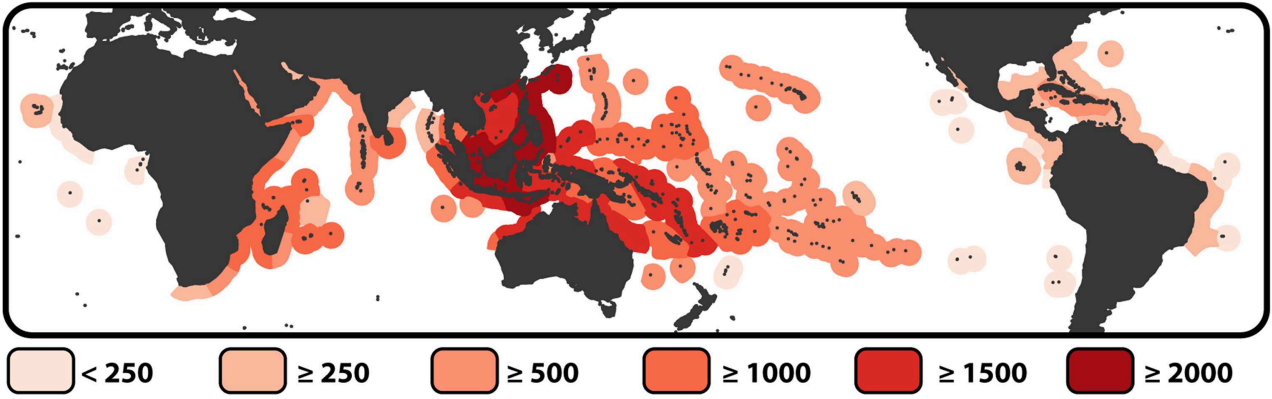

B Endemic Richness (by ecoregion)

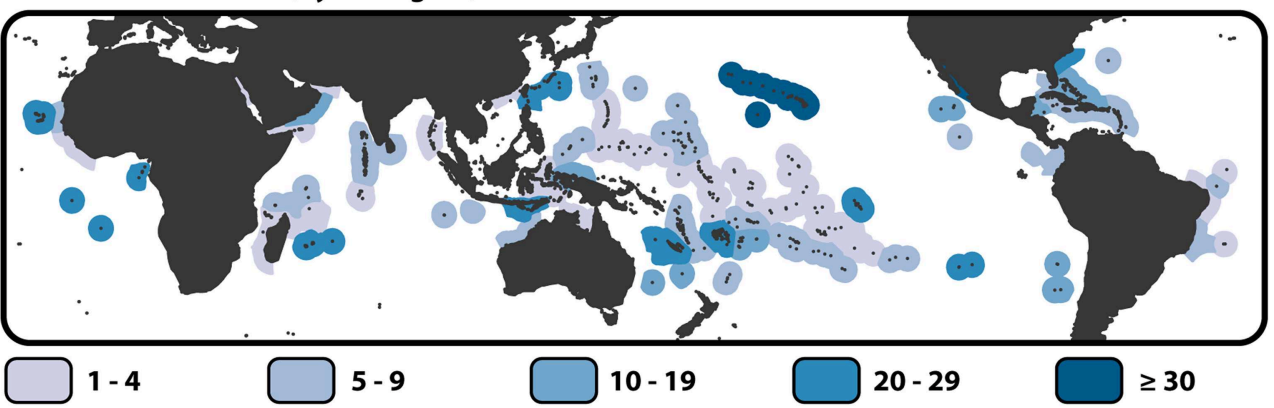

C Regional scheme

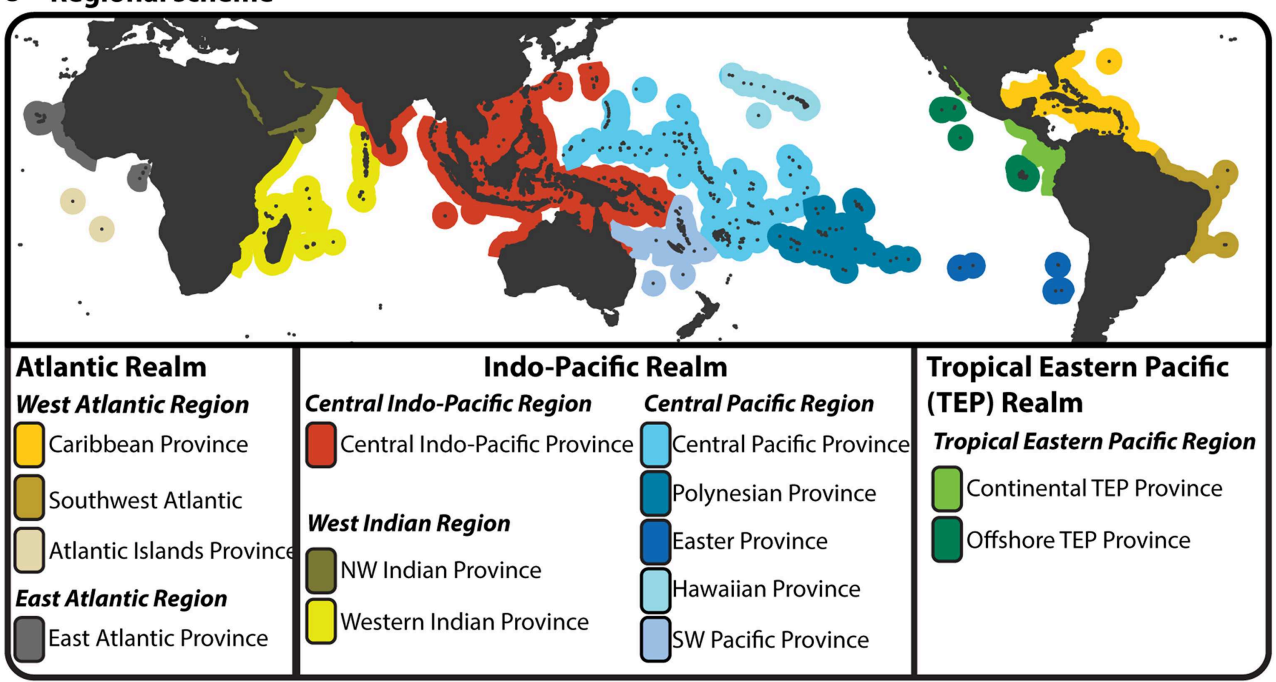

FIGURE 1 | Species richness, endemism and provinciality of tropical reef fishes. (A) Map of species biodiversity by tropical ecoregion (Spalding et al., 2007) with color gradient denoted areas of high species richness (dark red) to areas of low species richness (light red). (B) Map of endemic species by ecoregion. Under this scheme a species is endemic if it is only found in a single ecoregion, i.e., a regional assessment of endemic rather that designated by percent of area comparison (Hughes et al., 2002). Species richness and endemic estimates are based on species counts from the "checklist" × "all species" dataset of Kulbicki et al. (2013). (C) Biogeographic delineation of tropical Realms, Regions and Provinces based on species dissimilarity analysis of Kulbicki et al. (2013). This biogeographic scheme is based on checklists as base units (see Kulbicki et al., 2013), however here the scheme is imposed onto of the tropical ecoregions of Spalding et al. (2007). 